\section{Estudo \\ Ecidebate}

em Testã⿻

Planejamento
Revista Estudo \& Debate, Lajeado, v. 26, n. 1, 2019. ISSN 1983-036X

DOI: http://dx.doi.org/10.22410/issn.1983-036X.v26ila2019.1869

\title{
O EFEITO DA OBSERVAÇÁO E HONRA NA DESONESTIDADE DAS PESSOAS
}

\author{
Cleiton Rodrigo Arnhold ${ }^{1}$, George Alba ${ }^{2}$, Andriele Nahara Muller ${ }^{3}$
}

\begin{abstract}
Resumo: Evidências têm mostrado que praticamente todas as pessoas são desonestas, sendo que umas mais do que outras. As pessoas possuem uma bússola moral que define um limite de desonestidade baseado na sua percepçáo de diversos incentivos. Dois experimentos de campo investigaram o nível de desonestidade das pessoas. No primeiro experimento, os participantes se engajaram em uma olimpíada de matemática fictícia, onde havia a possibilidade de trapaça ao retornar a quantidade de respostas corretas da atividade. No segundo experimento, analisou-se a quantidade de pessoas que fizeram a devolução de troco excedente em uma situação de compra corriqueira. Os estudos testaram o quanto dois diferentes tipos de incentivos (moral e social) podem diminuir a desonestidade dos indivíduos. Os resultados do primeiro estudo mostraram que na possibilidade de trapacear, as pessoas foram desonestas, porém não muito. Já o segundo experimento mostrou que uma simples simulaçáo de estímulo social, a presença de um cartaz com a ilustração de olhos ao lado do caixa, reduziu a desonestidade e fez com que as pessoas devolvessem mais o troco excedente. Em ambos os estudos, a presença de códigos de honra não apresentou efeito na redução da desonestidade.
\end{abstract}

Palavras-chave: desonestidade, cultura de honestidade, incentivos morais, incentivos sociais.

\section{THE EFFECT OF OBSERVATION AND HONOR ON PEOPLE'S DISHONESTY}

\begin{abstract}
Evidences have shown that virtually all people are dishonest, some more than others. Humans have a moral compass that defines a limit of dishonesty based on their perception of many incentives. Two field experiments investigate the level of people's dishonesty by attending a fictitious math challenge and receiving extra change in a real purchase. The studies tested how much two different types of incentives (moral and social) can decrease the individuals' dishonesty level. The first study shows that, when cheating is possible, people are dishonest, but not much. The second study, however, shows that a simple simulation of social stimulus, as the presence of a poster with the illustration of eyes in front of the cashier, reduced the dishonesty and made more people return the extra change. In both studies, the presence of honor codes had no effect on reducing dishonesty.
\end{abstract}

Keywords: dishonesty, culture of honesty, moral incentives, social incentives.

1 Tecnólogo em Processos Gerenciais pelo IFRS e Empresário.

2 Doutor em Marketing pela UFRGS e Professor de Marketing do IFRS.

3 Mestranda em Marketing na UFRGS e Tecnóloga em Processos Gerenciais pelo IFRS. 


\section{Introdução}

Lucas vive em uma cidade de raízes europeias e acredita que as pessoas da sua região são mais honestas que no restante do país. Recentemente, ele foi fazer compras de escritório em uma loja da sua cidade. Ele faz o pagamento com uma nota de cem reais e recebe troco. Ao fazer a contagem, ele percebe que recebeu troco a mais do que deveria. Qual a probabilidade de Lucas devolver esse dinheiro extra? E se ele tivesse a sensação de estar sendo observado? E se ele se lembrasse do código de honra da cidade?

Muitas cidades brasileiras foram colonizadas por imigrantes europeus. Estas cidades, preservam alguns hábitos da cultura europeia e as pessoas acreditam ter herdado as tradiçóes, crenças e principalmente a honra de seus antepassados. Devido a organização de um plebiscito separatista independente nos três estados do sul do país, identificouse que muitas pessoas participaram deste evento. Especula-se que a alta participação das pessoas nesse movimento foi impactada por uma falácia de maior honestidade local, onde a independência territorial lhe traria um país mais justo, mais honesto, mais igualitário, mais "europeu”. Dessa forma, existe um senso comum nessas comunidades em que haveria maior honestidade que em outros locais.

Entretanto, o corpo de pesquisas na área de desonestidade refuta esta hipótese. Diversas pesquisas realizadas por Ariely (2012) mostram que a nacionalidade, a cultura, a religião, e a economia não influenciam no nível de desonestidade individual das pessoas. Essas pesquisas foram realizadas com israelenses, chineses, americanos, italianos, turcos, canadenses e ingleses. Os resultados mostraram que o volume de trapaça parece ser igual em todos os países. Segundo Hornuf, Tafurt e Ariely (2016) existe pouca variação na desonestidade generalizada entre os países. Em um experimento realizado com alunos do ensino superior de cinco países com economia e cultura ligeiramente distintos, (Alemanha, Estados Unidos, Portugal, China e Colômbia), esses autores identificaram que indivíduos destes cinco países que variavam bastante no índice de corrupção e aspectos culturais, eram igualmente desonestos em uma tarefa descontextualizada que permitia trapacear. Desta forma, constataram que a desonestidade em suas ações individuais não é influenciada pelos valores sociais, culturais e econômicos. Estas evidências podem ser testadas em âmbito regional ou até municipal, visto que os costumes e crenças poderão variar nesses contextos.

Segundo Ariely (2012), as atitudes das pessoas são movidas por uma avaliação de custo-benefício, que é conhecido como Modelo Simples do Crime Racional. O MOSCR representa um modelo simples de análise de custo-benefício, que é basicamente o resultado entre uma equação dos benefícios adquiridos por certa atitude, pelo risco de ser pego e o tamanho da punição que receberiam caso isso ocorra. Analisando por esta perspectiva, todas as pessoas seriam desonestas em algum momento, desde que o benefício fosse compensado pelo custo do crime. Por outro lado, Aronson (1969) e Baumeister (1998) destacam a ação do autoconceito que é a forma como as pessoas se veem e percebem a si mesmas. Pessoas que valorizam a honestidade e a tem como parte importante do seu sistema de recompensa interno, sofrem uma influência maior deste fator na sua tomada de decisão. As pessoas não querem ter uma autoavaliação negativa. Para elas, avaliar-se negativamente é desconfortável, percebendo que se agiram de forma incorreta, terão de rever sua conduta. Já as pessoas que se autoavaliaram positivamente, por manter-se nos limites da honestidade, tendem a 
fazer o que é certo, mesmo se tiverem que realizar grandes esforços ou abrir mão de valores monetários.

Sabendo da possibilidade de fraudes das pessoas, empresas devem utilizar-se de sistemas para reduzir os benefícios da desonestidade de clientes e funcionários aplicando estímulos consistentes. Além do âmbito privado, os governos têm a responsabilidade da criação de políticas públicas que incentivem as pessoas a serem mais honestas. Para tal, o benefício de ser desonesto deve ser menor do que o custo a ser pago se forem penalizados.

Para este trabalho, foram utilizados como base três experimentos: o primeiro de Ariely (2012), onde foram elaboradas 20 matrizes matemáticas a fim de verificar quantos acertos os participantes teriam em 4 minutos. Estes foram aleatoriamente separados em três grupos (controle, possibilidade de trapaça e possibilidade de trapaça com código de honra), onde no grupo de controle, as respostas foram corrigidas e o participante foi remunerado pelo seu desempenho. No grupo código de honra, o participante era exposto à um código de honra antes de iniciar a resolução da atividade, porém estas questôes não foram corrigidas, o participante simplesmente rasgava a folha e dizia a quantidade de acertos, sendo remunerado de acordo com o que havia dito. No grupo trapaça, o participante não recebia nenhum tipo de estímulo, resolvia o problema, rasgava a folha e reportava o resultado, recebendo o valor proporcional ao relatado.

O segundo experimento é de Bateson, Nettle e Roberts (2006), ambos da University of Newcastle, descrito em Ariely (2012). O experimento foi conduzido na cozinha do departamento de Psicologia da University of Newcastle. Lá, estavam disponíveis para os professores e demais funcionários chá, café e leite. No mural havia um recado dizendo que todos aqueles que consumissem o produto deveriam contribuir um valor em dinheiro para o "caixinha" do refeitório. Quando o mural estava decorado com flores, perceberam que o valor contribuído foi muito inferior ao valor deixado na caixinha quando havia imagens de olhos ao lado do recado. Justificando assim, que as pessoas tendem a ser menos desonestas quando tem a impressão de que estão sendo vigiadas.

O terceiro experimento foi idealizado por Azar, Yosef e Bar-Eli (2013) em um restaurante na Índia. O objetivo era identificar as condiçóes que faziam os clientes devolver o troco excedente que recebiam após realizarem o pagamento em dinheiro. Nesta ocasiáo, entregava-se de forma aleatória um troco excedente de $\$ 3.00$ e $\$ 12.00$. Foi possível verificar que apenas 64 clientes de um total de 192 (33\%) devolveram o troco que não os pertencia. Muitos outros fatores foram analisados: $51 \%$ dos clientes que receberam 12 dólares devolveram o troco, mas apenas $16 \%$ do total de pessoas que receberam 3 dólares devolveram o dinheiro. Fatores como qualidade do atendimento, demora em servir o prato e recorrência em frequentar o local também tiveram influência no resultado. Clientes recorrentes apresentaram um índice de honestidade superior ao dobro dos clientes que tomaram sua refeição pela primeira vez no restaurante. No final dos experimentos, identificou-se que as pessoas tendem a ser mais desonestas quando os valores monetários são menores, pois assim a desonestidade fica dentro do compasso moral.

Além disso, Ariely (2012) afirma que quanto maior a exposição de lembretes e códigos de honra, maior a chance de reduzir a desonestidade. Assim, lembrar padróes de moralidade no momento da tentação, pode ser muito eficaz para a redução do comportamento desonesto 
e até evitá-lo completamente. A partir dessas articulações, o objetivo do trabalho está alinhado com as descobertas de Bateson, Nettle e Roberts (2006) sobre senso de observação e Ariely (2012) sobre códigos de honra e possibilidade de trapaça.

O primeiro experimento buscou investigar o nível de desonestidade na resolução de matrizes em uma olimpíada de matemática "fictícia" entre três cidades do sul do Brasil, com possibilidade de trapaça. Já o segundo experimento buscou avaliar o impacto do código de honra e senso de observação em um experimento utilizando troco excedente, alinhado com a metodologia de Azar, Yosef e Bar-Eli (2013). Assim, o trabalho investiga o impacto da sensação de ser observado e a influência de um código de honra na desonestidade das pessoas em situaçóes corriqueiras. Estas situaçóes foram: receber troco excedente no momento de efetuar um pagamento e ter a possibilidade de apenas informar a quantidade de exercícios matemáticos resolvidos em uma tarefa sem a possibilidade de correção por um avaliador. Desse modo, este trabalho buscou ampliar o escopo dos estudos sobre desonestidade realizados anteriormente. Os estudos foram aplicados no contexto de cidades pequenas do Brasil, que preservam hábitos da cultura europeia.

\section{Referencial teórico}

\subsection{Desonestidade}

Mentir é da natureza humana, todas as pessoas o fazem (Ariely, 2012). Pequenas mentiras podem se transformar em problemas de grande escala com elevadas implicaçóes para a sociedade. Muitas das pequenas desonestidades diárias das pessoas podem parecer inofensivas, banais ou mesmo irrelevantes para o funcionamento da sociedade local, regional, nacional ou mesmo internacional. A junção de pequenas desonestidades tem um efeito multiplicador, gerando grandes problemas na gestão pública e diversos estudos corroboram que as pessoas realmente não entendem as causas e complexidade da desonestidade (Ariely, 2012).

Para Garrett, Lazzaro, Ariely \& Sharot (2016), desonestidade consiste em uma série de pequenas violaçóes/trapaças que se intensificam ao longo do tempo. A trapaça como é conhecida a "pequena desonestidade" faz parte de um grande campo de estudos sobre o tema de comportamento do consumidor. Bretan (2016) analisou estudos de Bowers (1964) e McCabe e Trevino (1993) sobre trapaças de estudantes de instituiçóes que tinham códigos de honra. $\mathrm{O}$ resultado confirmou a sequência de estudos de que o engajamento auto-relatado dos alunos em nove diferentes comportamentos acadêmicos desonestos era consistentemente mais baixo em escolas com códigos de honra do que naqueles sem códigos.

Segundo Mazar e Ariely (2006), desonestidade e trapaças são atitudes humanas comuns que afetam muitas atividades econômicas. Para Allingham e Sandmo (1972), as pessoas agem desonestamente de forma consciente e deliberada trocando os benefícios internos esperados, pelo preço a pagar gerado pelos atos desonestos. Desta forma, as pessoas se comportam desonestamente o suficiente para lucrar, mas honestamente o suficiente para iludir sua própria integridade (Mazar, Amir e Ariely, 2008). Nos Estados Unidos, estima-se que a sonegaçáo do imposto de renda representa em torno de 15\%, algo próximo de 300 
bilhōes de dólares anuais (Herman, 2005). Outro exemplo interessante vem das companhias de seguros, que registram um montante de 24 bilhóes de dólares anuais em pagamentos de sinistros fraudados, o que equivale a $10 \%$ de todas as ocorrências (Accenture, 2003).

Em um experimento realizado por Ariely (2012), jogadores de golfe estáo mais propensos a modificar a posição da bolinha com o taco, do que com o pé e por sua vez, estáo menos propensos a fazê-lo com a mão. Esse tipo de atitude faz com que a pessoa não se sinta tão responsável pela desonestidade, já que fisicamente está mais distante da bolinha ao movê-la com o taco. Outro estudo reportado por Ariely (2012) mostra que o uso do dinheiro em notas (dinheiro vivo), faz com que as pessoas estejam em contato direto com o mesmo, tornando-as menos desonestas, porém, ao lidar com vales, fichas, cartôes ou moedas virtuais, a desonestidade aumenta.

Em um estudo com acadêmicos americanos durante aproximadamente 15 anos, Bretag (2016) utilizou os dados temporais de Bowers (1964) e McCabe (2002) a fim de verificar se houve mudança de comportamente de trapaça acadêmica com o passar do tempo. Entre outras questóes, foram avaliadas atitudes desonestas de estudantes como fazer cópia dos trabalhos em casa, produzir ou fabricar dados de laboratório e copiar programas de computador de outras pessoas. Segundo resultados encontrados, os maiores trapaceiros foram influenciados pelas atitudes desonestas dos colegas, e alegaram que os professores das suas instituições não discutiram o código de honra em comparação aos alunos de escolas que apresentaram atitudes mais honestas (McCabe e Trevino, 1995). Para Bretag (2016), trapaceiros costumam terceirizar a responsabilidade pelos seus atos.

O comportamento humano, ao se tratar de desonestidade, apresenta dois modelos distintos. Segundo Ariely (2012), as atitudes das pessoas são movidas por uma avaliação básica de custo-benefício, que é conhecido como Modelo Simples do Crime Racional. O MOSCR, basicamente é o resultado entre uma equação dos benefícios adquiridos por certa atitude pelo risco de ser pego e a intensidade da punição que receberá. Para Hechter (1990) e Lewicki (1984), no comportamento humano, as pessoas consideram apenas três aspectos ao passar em frente a uma loja de conveniência: o valor total em dinheiro que poderiam ter se roubassem o estabelecimento, a probabilidade de serem flagrados e o tamanho da punição que receberiam caso fossem pegos. Assim, a atitude futura depende diretamente desta avaliação. Cada oportunidade de trapaça terá diferentes variáveis, aumentando ou diminuindo os incentivos e puniçóes, alterando o processo de avaliaçáo da oportunidade, gerando açóes distintas em cada caso. Segundo Ariely (2012), as pessoas devem trapacear mais quando percebem a chance de ganhar mais dinheiro sem serem pegas ou punidas.

Por outro lado, existe outro modelo de comportamento humano relacionado à desonestidade. Para Aronson (1969) e Baumeister (1998), todas as ações das pessoas são influenciadas pelo seu autoconceito, que é a forma como as pessoas veem e percebem a si mesmas. Pessoas que valorizam a honestidade e a tem como parte importante do seu sistema de recompensa interno, sofrem uma influência maior deste aspecto na sua tomada de decisão. As pessoas não querem ter uma autoavaliação negativa. Para Burnham e Johnson (2005), os seres humanos estão fortemente preocupados com as consequências reputacionais do comportamento. Avaliar-se negativamente é desconfortável, percebendo que agiram de forma incorreta, terão de rever suas atitudes. Já as pessoas que se autoavaliaram positivamente 
por manter-se dentro do padrão honesto, tendem a fazer o que é certo, mesmo se tiverem que realizar grandes esforços ou abrir mão de valores monetários.

Alguns fatores podem contribuir para reduzir ou mesmo controlar a desonestidade das pessoas. Segundo Ariely (2012), algo tão simples quanto lembrar padróes de moralidade no momento da tentaçâo, pode ser muito eficaz para a diminuição do comportamento desonesto e até evitá-lo completamente. Quanto maior a exposição de lembretes, códigos de hora, mandamentos, códigos de condutas em ambientes diversos, maior a chance de reduzir a desonestidade. Outro fator que contribui para o controle da desonestidade é gerar uma sensação de que as pessoas estejam sendo observadas (vigiadas), tanto por câmeras de vigilância, banners ou um simples cartaz com um par de olhos.

Muitas pessoas acreditam que a cultura, religião e outros fatores regionais definem o comportamento honesto ou desonesto das pessoas. Ariely (2012) mostra que fatores como a nacionalidade, a cultura, a religião, e a economia não influenciam no nível de desonestidade individual dos seres humanos. Uma pesquisa realizada por Hornuf, Tafurt e Ariely (2016), com israelenses, chineses, americanos, italianos, turcos, canadenses e ingleses para avaliar justamente o comportamento individual desonesto, mostrou que o volume de trapaça parece ser igual em todos os países.

Segundo Hornuf, Tafurt e Ariely (2016) existe pouca variação na desonestidade generalizada entre os países. Nesse estudo, realizado com alunos de ensino superior de cinco países com economia e cultura ligeiramente distintos, (Alemanha, Estados Unidos, Portugal, China e Colômbia), identificaram que indivíduos de cinco países que variavam consideravelmente em seus níveis de corrupção e valores culturais eram igualmente desonestos em uma tarefa descontextualizada que permitia trapacear. Desta forma, constatase que a desonestidade individual das pessoas é pouco afetada por valores sociais, culturais e econômicas.

Quando se refere a grupos, pessoas percebem a honestidade/desonestidade de forma distinta analisando apenas a profissão. Em uma pesquisa do Instituto Gallup (2015), constatou-se que $85 \%$ dos americanos consideram as enfermeiras as profissionais mais honestas e éticas no mercado nacional, seguidas pelos farmacêuticos, médicos, professores de ensino médio e policiais, todos estes com percentual superior a 50\%. Na outra ponta da tabela, membros do Congresso, vendedores de carros, lobistas e operadores de telefonia móvel estão abaixo de $10 \%$ no conceito de honestidade.

Segundo a pesquisa de DePaulo e Kashy (1998), ao analisarem as mentiras diárias das pessoas, identificaram que elas mentem menos para aqueles que estão mais próximos, que encontram com mais frequência, e que conhecem por um período mais longo. Isso significa que existe uma tendência de que as pessoas sejam menos desonestas em ambientes familiares e estabelecimentos que frequentam diariamente, já que isso poderia afetar a relação de confiança entre as partes.

\subsection{Cultura de honestidade}

Muitas cidades que compóem os estados do sul do Brasil, tem descendência germânica ou italiana. Os governantes destas cidades incentivam a preservação da cultura e os valores 
europeus. Em muitas escolas municipais destas cidades, a língua alemã faz parte da grade curricular. Alunos são expostos periodicamente ao contato com europeus que vêm visitar essa regiáo ou mesmo através de projetos de intercâmbio online, onde alunos de escolas locais conversam com alunos de escolas públicas da Alemanha. Analisando estes aspectos, essas cidades supostamente teriam uma visão "europeia", pela sua "localização privilegiada" e "população especial", que acredita ser mais trabalhadora, mais educada e também mais honesta do que o restante do país.

Como citado anteriormente, as pessoas tendem a preocupar-se com os valores e normas da sua sociedade (Campbell, 1964), as quais servem de referência interna para controlar o seu comportamento. Como cada sociedade possui distintas normas e culturas, este autoconceito é diferente em cada pessoa, mas muito influenciado pela regiáo em que vive. Em um estudo recente, Fisman e Edward (2007) descobriram que os diplomatas de países de alta corrupção acumulavam significativamente violações de estacionamento não remuneradas, justificando assim que a desonestidade individual é oriundo das açóes praticadas em seus próprios países de origem. Como a cultura é oriunda da educação, Mazar, Amir e Ariely (2008), chamam a atenção das sociedades para que não deixem de investir seus esforços educacionais na criaçáo e desenvolvimento dos padrôes morais das pessoas e que estes façam parte das normas culturais praticadas por todos.

Por outro lado, a cultura de honestidade não é generalizada, isto é, não se pode afirmar que todas as pessoas expostas aos mesmos ambientes e estímulos irão agir da mesma forma. Para Bucciol et al. (2013), em um estudo de passageiros de ônibus na Itália, verificou-se que os homens são mais propensos a viajar sem bilhete do que as mulheres, o que quer dizer que o gênero pode apresentar influência nas atitudes das pessoas, mesmo que ambos residam na mesma região/país.

Conforme o experimento de Bateson, Nettle e Roberts (2006), descrito anteriormente, as pessoas desenvolvem um senso de observação, quando percebem imagens de olhos no ambiente que estáo. A fim de encontrar formas de diminuir ou mesmo controlar a desonestidade humana, foram elaboradas duas hipóteses que buscam avaliar o quanto os índices de desonestidade sáo influenciados por um código de honra (incentivo moral) e a sensaçáo de estar sendo vigiado (incentivo social).

As hipóteses a serem testadas são:

H1 - A exposiçâao ao código de honra da cidade diminui o índice de desonestidade.

H2 - A sensação de estar sendo observado diminui o índice de desonestidade.

\section{Processos metodológicos}

Devido a alguns pesquisadores como Bateson, Nettle e Roberts (2006), Ariely (2012) e Azar, Yosef e Bar-Eli (2013) terem feito anteriormente estudos sobre desonestidade, que foram base para este artigo, buscou-se um método que fosse capaz de capturar e analisar o impacto de causa e efeito da desonestidade. Deste modo, este trabalho é composto por dois estudos experimentais que foram realizados de forma separada, porém com objetivos semelhantes, em contextos distintos dos trabalhos já realizados. Os precedimentos que 
foram empregados no dois estudos estão de acordo com os princípios éticos que norteiam a Resolução 466/2012 do Conselho Nacional de Saúde.

\subsection{Estudo 1}

$\mathrm{O}$ primeiro estudou analisou a atitude das pessoas de trapacear ao participarem de uma olimpíada de matemática regional "fictícia", as pessoas foram convidados a participar da competição de resolução de exercícios matemáticos. Os pesquisadores visitaram a casa dos participantes convidando-os para participar de uma Olimpíadas de Matemática entre três cidades. Os participantes foram sorteados a partir de mapas da cidades e depois foram aleatorizados em três diferentes grupos: controle, possibilidade de trapaça e código de honra com exposição de código de honra). Utilizou-se o mapa dos lotes urbanos fornecidos pelas prefeituras das três cidades, numerou-se individualmente cada terreno e através de uma macro do Excel, realizou-se o sorteio dos lotes a serem pesquisados, com o propósito de uma amostra aleatória possibilitando a mesma chance de participação para todos os habitantes destes municípios. Para garantir a realidade estatística do experimento, regras foram criadas para lidar com variáveis estranhas. Ao encontrar um lote vazio ou mesmo quando os moradores não quiseram participar do teste, o pesquisador deveria se dirigir ao lote da sua direita, até conseguir realizar a pesquisa, além disso, exigiu-se uma escolaridade mínima para a participação do experimento (fundamental completo).

O teste matemático consistia em uma tabela com 20 matrizes, onde o participante deveria encontrar dois numerais que somados o resultado daria 10. Para engajar os respondentes à pesquisa, foi informado antes da realizaçáo do teste que eles estavam participando de uma olimpíada de matemática que seria disputada entre os habitantes das três cidades. A cada acerto, os participantes receberam uma recompensa financeira de $R \$$ 0,25 , que serviu como estímulo financeiro.

No grupo de controle, os participantes simplesmente recebiam matrizes matemáticas para resolver, após 4 minutos, o pesquisador fazia a correção e pagava-lhe o valor correspondente ao número de acertos. No grupo com possibilidade de trapaça, os participantes recebiam as matrizes e eram informados de que elas não seriam corrigidas. No grupo do código de honra, também com possibilidade de trapaça, os participantes eram expostos a um código de honra da cidade ("[cidadãos da cidade] são pessoas honradas, trabalhadoras e solidárias. Nossas atitudes nos mantêm fortes e perseverantes!”) antes da realização do teste e era lhes informado que as questóes também não seriam corrigidas. A variável dependente foi a quantidade de matrizes que cada participante acertou (grupo de controle) ou alegava ter acertado (grupos com possibilidade de trapaça). Houve um registro de 432 participantes distribuídos entre moradores de três cidades gaúchas com população inferior a 50 mil pessoas colonizadas por alemães. Este estudo teve a participação de 432 pessoas, sendo que 134 pertenceram ao grupo de controle, 137 ao código de honra e 161 ao grupo da trapaça. Essa distribuiçáo foi feita aleatoriamente, registrando 227 mulheres e 205 homens. Os moradores que não estavam em casa ou que não quiseram responder não foram contabilizados. 


\subsection{Estudo 2}

Nesse experimento de campo, os clientes entravam na loja, escolhiam seus produtos e se dirigiam ao caixa para realizar o pagamento. Quando efetuavam o pagamento em dinheiro, o atendente recebia o valor, emitia a nota fiscal e a entregava troco excedente de $\mathrm{R} \$ 2,00$ (sempre em nota, nunca em moedas para padronizar o experimento). Ao lado do caixa havia um expositor com uma das três condições. As pessoas efetuavam uma compra em uma loja e quando houvesse possibilidade de receber troco excedente, o caixa da loja o fazia.

Ao lado do caixa, onde era efetuado o pagamento das compras, havia um expositor com uma folha contendo o estímulo correspondente à sequência aleatória dos estímulos, que foi pré-definida antes da realizaçáo em campo. Quando o cliente entrava no estabelecimento, era atendido por um dos vendedores e logo após encaminhado para o caixa junto da sua mercadoria. Ao realizar o pagamento em dinheiro, recebia a nota fiscal e o seu troco com uma nota de $\mathrm{R} \$ 2,00$ excedente e aguardava-se a reação do cliente para verificar se ele faria a devolução do dinheiro excedente ou se ficaria com ele.

$\mathrm{Na}$ primeira condição, o cliente entra na loja, escolhe seu produto e faz o pagamento em dinheiro, sem receber nenhum tipo de estímulo, o que colocava o cliente na condição de controle. Ao lado do balcão, havia apenas um pequeno cartaz escrito obrigado pela preferência. Na segunda condição, o cliente foi exposto a um lembrete com o código de honra da cidade. Este lembrete estava localizado exatamente no mesmo local onde anteriormente estava o outro cartaz. Já na terceira, o cliente foi exposto a uma imagem com um par de olhos, simulando a impressão de que havia alguém o observando, também exposto sobre o balcão ao lado do caixa.

Ao todo, 146 pessoas participaram do experimento, onde 44 compuseram o grupo de controle, 49 visualizaram o cartaz com os olhos e 53 visualizavam o código de honra (o mesmo código utilizado no experimento 1). Logo após a saída do cliente, o atendente registrava alguns dados dos participantes. A idade era extraída do sistema de gestão instalado no computador a qual já continha o cadastro dos clientes. Para clientes novos, o cadastro era realizado antes de iniciar o procedimento de pagamento. Devido a natureza deste experimento de campo, e considerando que a principal medida foi o comportamento observado, o estudo não apresentou riscos para os participantes. Todas as pessoas que realizaram um pagamento em espécie, nos dias em que o estudo estava sendo feito, foram contabilizadas para a amostra.

\section{Resultados e análises}

\subsection{Estudo 1}

No estudo, 134 pessoas (31\%) participaram do grupo controle, que depois de 4 minutos disponíveis para realizar as matrizes, o pesquisador corrigia os exercícios, 137 pessoas $(32 \%)$ participaram do grupo código de honra, visualizando uma folha com código de honra da sua cidade (as matrizes náo foram corrigidas) e 161 pessoas (38\%) participaram 
do grupo trapaça, no qual eles só precisam informar ao pesquisador a quantidade de acertos. Não foi necessário descartar participantes da amostra para a realização das análises.

Uma análise de variância (ANOVA) confirmou variação significativa entre as três condiçóes $(\mathrm{F}(2,429)=7,06, \mathrm{p}<0,01)$. Um teste post hoc mostrou que o grupo que tinha possibilidade de trapaça e o grupo controle diferiram de forma significativa em $\mathrm{p}$ $<0,05$; O grupo do código de honra não foi significativamente diferente dos outros dois grupos. A média de acertos de cada grupo pode ser visualizada na Figura 1. Ao analisar se havia diferença entre homens e mulheres no nível de trapaça, os testes não se mostraram significativos.

Figura 1 - Média de acertos de cada grupo:

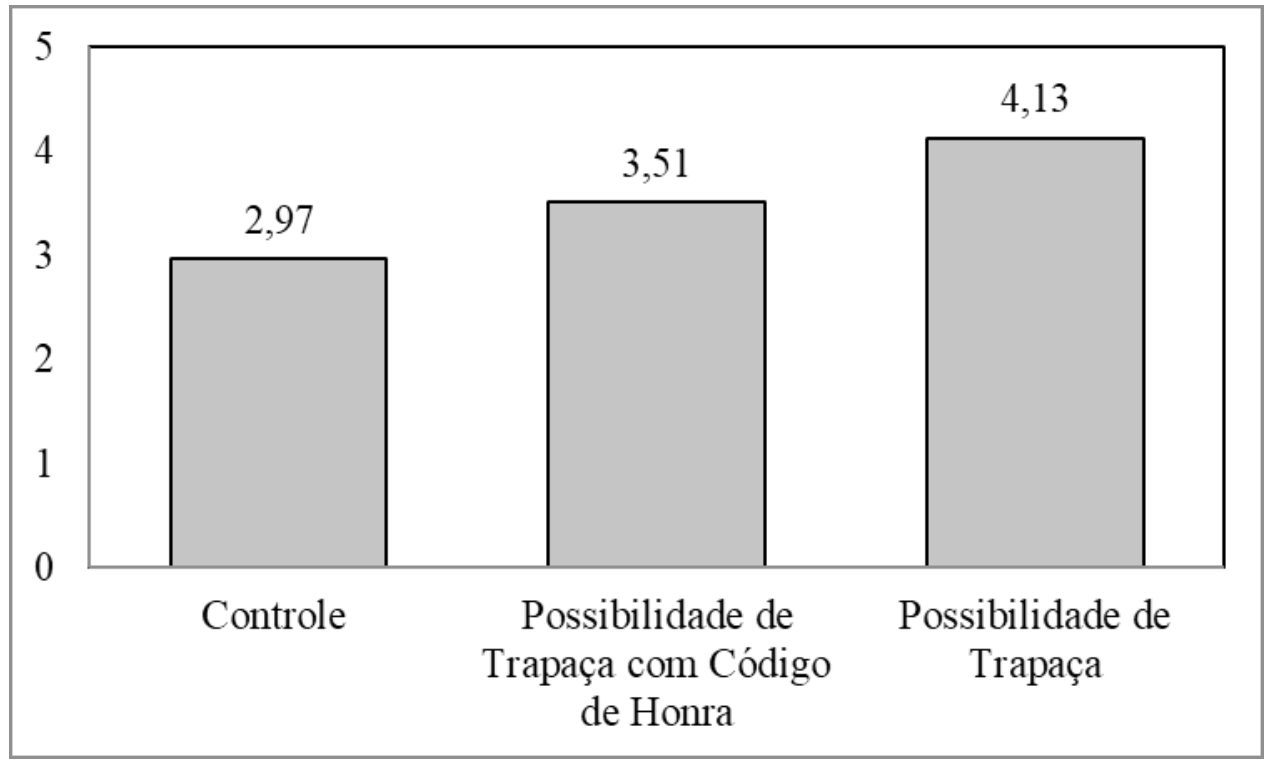

\subsection{Estudo 2}

Neste experimento, houve a participação de um total de 146 pessoas com média de idade igual a 41,5 anos, destes, 119 homens (82\%). Constatou-se que 95 pessoas (65\%) eram clientes recorrentes do estabelecimento comercial, já 51 (35\%) estavam realizando sua primeira compra neste local. Na Figura 2, é possível visualizar graficamente a relação entre cada estímulo e a ação do cliente em devolver o troco excedente: 
Figura 2 - Percentual de pessoas que devolveram o troco excedente:

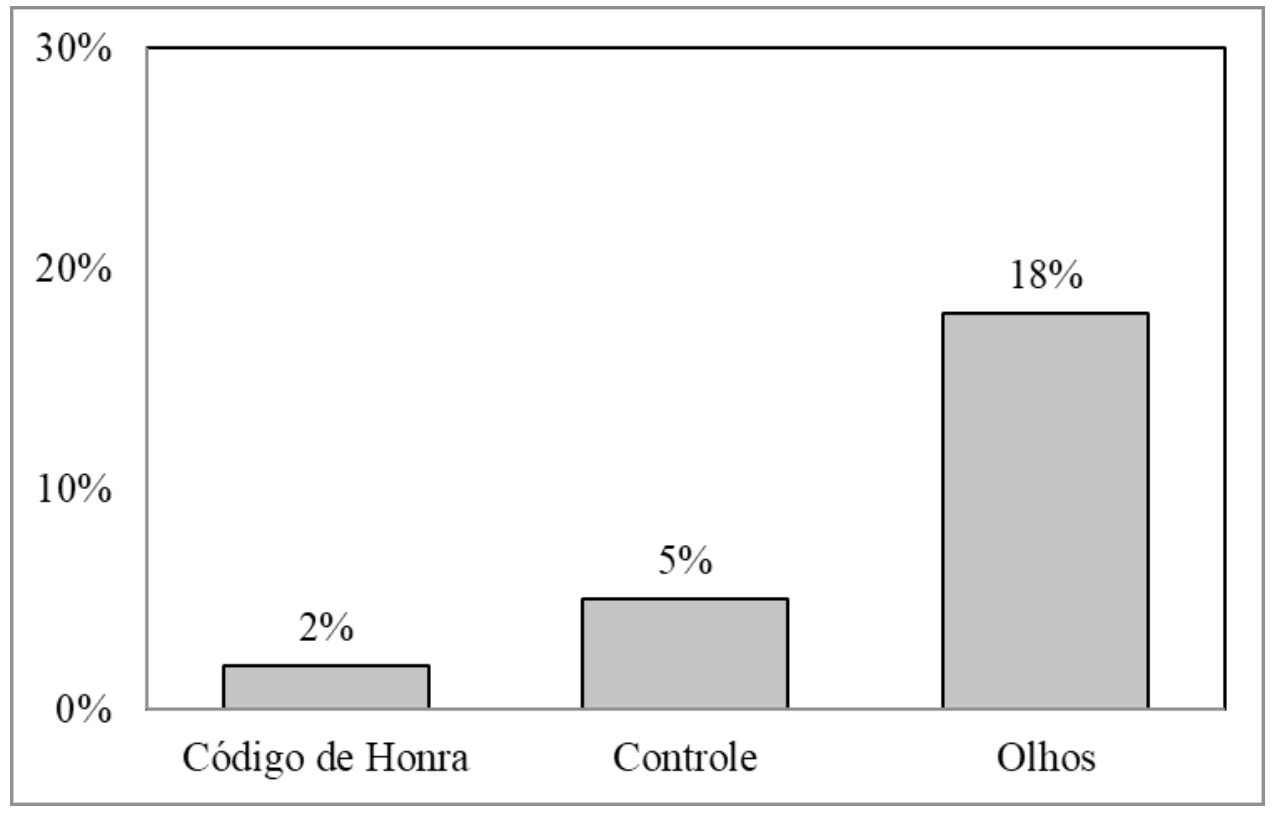

No estudo, 44 pessoas (30\%) participaram do grupo de controle, que visualizavam um cartaz com a frase "Obrigado pela preferência, 49 (34\%) visualizavam o cartaz com o desenho dos olhos e $53(36 \%)$ visualizavam o código de honra. Deste total de participantes, apenas 12 pessoas $(8 \%)$ devolveram o troco excedente.

Em um teste qui-quadrado entre todos os estímulos (controle, olhos e código de honra) com a variável dependente (ação do cliente), o número de pessoas que devolveu o troco variou significativamente entre as condiçóes $\left(X^{2}(2)=10,294, p<0,05\right)$. $O$ gênero teve impacto significativo na variável dependente $\left(\mathrm{X}^{2}(1)=4,266, \mathrm{p}<0,05\right)$, sendo que uma proporção maior de mulheres devolveu o troco excedente. Não houve diferença entre clientes recorrentes.

Para realizar as análises da regressão logística binária, os participantes do grupo de controle receberam a codificação zero (0), para ausência de ação, o grupo do estímulo dos olhos, receberam o valor um (1) para a existência da ação. A mesma regra foi utilizada no grupo que recebeu o estímulo do código de honra. Para o gênero, atribuiu-se o valor de zero (0) para os homens e um (1) para as mulheres. Para os clientes recorrentes, foi atribuído valor zero (0) e clientes novos o valor um e pôr fim a variável dependente foi atribuído valor zero (0) para os clientes que náo devolveram o troco excedente e valor um (1) para os que devolveram.

Foi realizada uma regressão logística binária para verificar se a presença de um estímulo social (presença de um cartaz com olhos) é preditor da ação positiva de devolver o troco excedente. Ao comparada com a condição de controle, apresentou significância estatística, conforme modelo: $\left[\mathrm{X}^{2}(3)=9,416 ; \mathrm{p}<0,05, \mathrm{R}^{2}\right.$ Nagelkerke $\left.=0,186\right]$. A presença deste 
estímulo foi um preditor significativo para a probabilidade de devolver o troco excedente $(\mathrm{OR}=6,537$; IC 95\% = 1,182-36,140).

$\mathrm{O}$ gênero apresentou influência na variável dependente $(\mathrm{OR}=5,381$; IC $95 \%=$ 1,161 - 25,863), porém não houve diferença entre os clientes novos e frequentes para explicar a ação do cliente. A variável independente do estímulo dos olhos, assim como o gênero são significativos para o aumento da honestidade $(p<0,05)$. A presença de um cartaz com o desenho de olhos aumenta a probabilidade de devolução do troco excedente em 6,54 vezes. Quando o cliente é do sexo feminino, existe uma chance de 5,48 vezes maior das mulheres devolverem o troco excedente se comparado com os homens $(\mathrm{p}<0,05)$. Não há diferença entre clientes recorrentes e novos clientes no comportamento de devolução do troco excedente.

Foi realizada outra regressão logística binária para verificar se a presença do código de honra é preditor da ação positiva de devolver o troco excedente. $\mathrm{O}$ modelo contendo o estímulo não foi significativo: $\left[\mathrm{X}^{2}(3)=4,344 ; \mathrm{p}>0,05, \mathrm{R}^{2}\right.$ Nagelkerke $\left.=0,182\right]$. A presença do código de honra não foi um preditor significativo do comportamento honesto ( $\mathrm{p}>$ 0,05). Nessa análise, o gênero também não teve impacto $(\mathrm{p}>0,05)$.

Em outra análise de regressão logística binária para verificar se a presença dos olhos é estatisticamente diferente do código de honra na previsão da ação positiva do cliente em devolver o troco excedente, verificou-se um modelo significativo: $\left[\mathrm{X}^{2}(2)=14,646\right.$; $\mathrm{p}<$ $0,001, \mathrm{R}^{2}$ Nagelkerke $\left.=0,282\right]$. A presença do estímulo do cartaz com o desenho de olhos foi um preditor significativo $(\mathrm{OR}=20,110$; IC 95\% = 2,064 - 195,934). Novamente, o gênero teve influência no comportamento $(\mathrm{OR}=8,059$; IC 95\% $=1,491-43,552)$. A presença dos olhos aumenta em 20,11 vezes a chance do cliente devolver o troco excedente. Já as mulheres, têm 8 vezes mais chance de devolver o troco em comparação aos homens.

\section{Conclusão}

Após a análise dos dados, é possível afirmar que a presença da possibilidade de trapaça faz com que as pessoas tomem uma atitude mais desonesta, como foi possível perceber na variação da média de acertos das matrizes entre os grupos do primeiro experimento. Quando a pessoa tem a consciência de que não terá chance de ser pêga em sua fraude, não terá punição e ao mesmo tempo, aumentará seu ganho financeiro ou moral, as pessoas terão maior probabilidade em trapacear, porém em níveis moderados. A desonestidade tende a ficar dentro de um compasso moral aceitável para que essas açóes não afetem seu autoconceito.

Assim como no experimento original de Ariely (2012), as pessoas do grupo com possibilidade de trapaça apresentaram uma média de acerto $39 \%$ superior ao grupo de controle (que não tinham possibilidade de trapaça). Já o grupo com possibilidade de trapaça, expostas ao código de honra, apresentaram uma média de acertos $18 \%$ superior ao grupo de controle, porém nesse estudo, essa diferença não foi significante.

A presença de um estímulo como um cartaz com olhos, dando a impressão de que o cliente estava sendo vigiado, diminuiu consideravelmente a desonestidade das pessoas ao comparar com a ausência do mesmo (grupo de controle). A presença de um código de 
honra, porém, não impactou na desonestidade das pessoas. Quando há a presença de um código de honra, segundo Ariely (2012), o cliente deveria apresentar uma reaçấo similar à presença do estímulo dos olhos, já que a pessoa tende a manter a sua honestidade quando lembrada constantemente de ser honrada, ética e honesta (código de honra). Porém, esse padrão não foi confirmado neste experimento, mostrando que algumas açôes podem não ser eficazes no combate à desonestidade.

Em alguns relatos dos clientes ao ter contato com o código, argumentavam que os habitantes da cidade não tinham atitudes que condizem com o que estava escrito, ou mesmo que não reconheceram este código como sendo representativo da sua cidade, o que torna evidente que sua ineficácia pode ser explicada pela falta de crença do texto que estava exposto aos clientes. Ainda segundo Hornuf, Tafurt e Ariely (2016), não há muita variação na desonestidade individual das pessoas ao redor do mundo, o que pôde ser confirmado neste experimento, já que o percentual de devolução do dinheiro excedente foi de $16 \%$ no experimento realizado por Azar, Yosef e Bar-Eli (2013) em um restaurante na Índia, o que ficou muito próximo deste experimento $(12,17 \%)$ quando analisado apenas o troco excedente de 3 dólares e 2 reais respectivamente, o que pode ser entendido como valores monetários baixos.

Um extenso corpo de pesquisa vem ampliando o entendimento sobre a desonestidade em diversos contextos. As evidências sugerem que a variabilidade nos níveis de desonestidade dos seres humanos tem pouca ou nenhuma relação com a localização geográfica e a cultura per se. Dessa forma, é possível que exista uma explicação biológica, como a sustentada por Dawkins e Kreb (1978) na sua abordagem evolucionista. Os autores sugerem que indivíduos da mesma espécie agem, a partir de uma visão de "gene egoísta", como se os seres de uma mesma espécie tentassem enganar um ao outro na disputa por melhores condiçóes de sobrevivência e reprodução.

Assim como a teoria de Hornuf, Tafurt e Ariely (2016) existe pouca variação na desonestidade generalizada entre os países. Os autores realizaram um experimento em cinco países com economia e cultura ligeiramente distintos, (Alemanha, Estados Unidos, Portugal, China e Colômbia). Ariely (2012) realizou outro estudo em Israel, China, Estados Unidos, Turquia, Canadá e Inglaterra. Em ambos os estudos, os resultados são muito similares, aos resultados encontrados neste trabalho.

A hipótese $\mathrm{H} 1$ não foi confirmada, sendo que os resultados mostraram que a presença do estímulo do código de honra não alterou significativamente a honestidade dos participantes em nenhum dos dois experimentos. Contudo, a hipótese $\mathrm{H} 2$ foi aceita, confirmando que a percepçáo dos clientes de estarem sendo observados aumentaria a honestidade, o que foi comprovado nas análises realizadas e interpretadas do segundo experimento.

Para futuras pesquisas, é recomendável replicar este experimento retornando um maior valor no troco a fim de verificar se há alteração na desonestidade das pessoas ao modificar a quantidade de dinheiro. Além disso, pode-se fazer este experimento em um ambiente onde há uma maior circulação de mulheres para reproduzir os resultados encontrados em um ambiente de consumo com presença mais equilibrada entre homens e mulheres. Outros estímulos podem ser utilizados para verificar o que pode influenciar 
na decisão das pessoas, como a presença de uma câmera de vigilância e uma placa com os dizeres "você está sendo filmado". Pode-se, também, realizar o experimento em ambiente onde o cliente fica mais sozinho e tem mais tempo para refletir sobre a sua ação (como no experimento de Bateson, Nettle e Roberts (2006)), a fim de verificar se a pessoa muda a sua decisão caso tenha tempo de refletir e analisar os benefícios, risco e tamanho da punição. Outros métodos de pesquisa também podem ser empregados a fim de compreender com maior profundidade os sentimentos e emoçōes que as pessoas sentem em situações que englobam a desonestidade, assim como as razóes pelas quais as pessoas agem de tal forma.

Este trabalho tem como primeira contribuição avançar os estudos realizados anteriormente sobre desonestidade, ampliando o escopo dos países e realizando o estudo em cidades menores, identificando padrōes idênticos aos demais. Como segunda contribuição, o experimento comprovou que alguns estímulos podem contribuir para o controle da desonestidade, desta forma, diversas organizaçōes podem se beneficiar destes resultados, reduzindo as perdas com trapaças dos clientes e também dos funcionários. Órgáos governamentais podem usufruir destes resultados para a criaçáo de políticas públicas que aumentem a participação da população no controle e combate à corrupção na gestão pública, criando um senso de observaçáo nos gestores.

\section{Referências}

ACCENTURE. One-Fourth of Americans Say It's Acceptable to Defraud Insurance Companies. Disponível em: http://www.accenture.com/xd/xd.asp. Acessado em 13 jun. 2017.

ALLINGHAM, M. G., SANDMO, A. Income tax evasion: a theoretical analysis. Journal of Public Economics, v. 1, p. 323-338, 1972.

ARIELY, D. A mais pura verdade sobre a desonestidade. Rio de Janeiro: Elsevier, 2012.

ARONSON, E. A Theory of Cognitive Dissonance: A Current Perspective. Advances in Experimental Social Psychology, v. 4, p. 1-34, 1969.

AZAR, O. H., YOSEF, S., BAR-ELI, M. Do customers return excessive change in a restaurant? A field experiment on dishonesty. Journal of Economic Behavior and Organization, v. 93, p. 219-226, 2013.

BATESON, M., NETTLE, D., ROBERTS, G. Cues of being watched enhance cooperation in a real-world setting. Biology Letters, v. 2, p. 412-414, 2006.

BAUMEISTER, R. F. The self. The handbook of social psychology, v. 1, n. 4, p. 680740, 1998.

BRETAG, T. Handbook of academic integrity. Handbook of Academic Integrity, 1-1097, 2016. 
BUCCIOL, A., LANDINI, F., PIOVESAN, M. Unethical behavior in the field: demographic characteristics and beliefs of the cheater. Journal of Economic Behavior and Organization, v. 93, p. 248-257, 2013.

BURNHAM, T., JOHNSON, D. D. P. The evolutionary and biological logic of human cooperation. Analyse Kritik, v. 27, p. 113-135, 2005.

CAMPBELL, E. Q. The Internalization of Moral Norms. Sociometry, v. 27, n. 4, p. 391-412, 1964.

DAWKINS, R., KREBS, J. Krebs, John; Davies, N. B., eds. Animal signals: information or manipulation? Behavioural Ecology: an evolutionary approach. Blackwell, p. 282-309, 1978.

DEPAULO, B.M.; KASHY, D.A. Everyday lies in close and casual relationships. Journal of Personality and Social Psychology, v. 74, p. 63-79, 1998.

FISMANN, R., EDWARD, M. Corruption, Norms, and Legal Enforcement: Evidence from Diplomatic Parking Tickets. Journal of Political Economy, v. 115, n. 6, p. 10201048, 2007.

GALLUP. Notícias. Disponível em: http://news.gallup.com/poll/187874/americansfaith-honesty-ethics-police-ebounds.aspex?g_source=honesty\&g_medium=search\&g_ campaign-tiles Acessado em: 04 jun. 2017.

GARRETT, N., LAZZARO, S. C., ARIELY, D., SHAROT, T. The brain adapts to dishonesty. Nature Neuroscience, 19(12), 1727-1732, 2016.

HECHTER, M. The Attainment of Solidarity in Intentional Communities. Rationality and Society, v. 2, n. 2, p. 142-55, 1990.

HERMAN, T. Study Suggests Tax Cheating Is on the Rise; Most Detailed Survey in 15 Years Finds \$250 Billion-Plus Gap; Ramping Up Audits on Wealthy. The Wall Street Journal, 2005.

HORNUF L., TAFURT J., ARIELY D. Cut from the same cloth: Similarly dishonest individuals across countries. Journal of Cross-Cultural Psychology, v. 47, n. 6, p. 1-17, 2016

LEWICKI, R. J. Lying and Deception: A Behavioral Model. Negotiation in Organizations, Bazerman MH, Lewicki RJ. Sage Publications: Beverly Hills, CA. p. 68-90, 1984.

MAZAR, N., ARIELY, D. Dishonesty in everyday life and its policy implications. Journal of Public \& Marketing, v. 25, p. 117-126, 2006. 
MAZAR, N.; AMIR, O.; ARIELY, D. The Dishonesty of Honest People: A Theory of Self-Concept Maintenance. Journal of Marketing Research, v. 45, p. 633-688, 2008.

MCCABE, D. L., TREVINO, L. K. Cheating among business students: A challenge for business leaders and educators. Journal of Management Education, 19(2), 205-218, 1995. 